\title{
FÉLIX JOSÉ WEIL: UN LATINOAMERICANO EN LA FUNDACIÓN DE LA ESCUELA DE FRANKFURT OMAR GARCÍA CORONA ${ }^{1}$
}

RESUMEN: La primera Escuela de Frankfurt es conocida como una de las más importantes expresiones del marxismo occidental desarrollada en Europa y los Estados Unidos a lo largo el siglo XX. Autores como Theodor W. Adorno, Max Horkheimer o Herbert Marcuse son conocidos por sus investigaciones sociales y su crítica a la modernidad. No obstante, la pregunta clave en este ensayo es la siguiente: ¿Qué relación guarda América Latina con aquella primera generación de jóvenes intelectuales interesada en abrir un instituto para la investigación social? O más específicamente ¿Qué relación guarda América Latina con la primera Escuela de Frankfurt? Descubrimos en la figura de Félix José Weil, nacido en Argentina, un pensador de formación marxista de amplios alcances que jugaría un papel central para la formación, en sentido teórico y económico, de la afamada Escuela; personaje, sin embargo, marginado y casi desconocido en los estudios de la filosofía crítica.

PALABRAS CLAVE: mecenas, marxismo, IFS, fundación, Argentina.

ABSTRACT: The first Frankfurt School is known as one of the most important expressions of Western Marxism developed in Europe and the United States throughout the 20th century. Authors such as Theodor W. Adorno, Max Horkheimer or Herbert Marcuse are known for their social research and their criticism of modernity. However, the key question in this essay is the following: What relationship does Latin America have with that first generation of young intellectuals interested in opening an institute for social research? Or more specifically, what relationship does Latin America have with the first Frankfurt School? We discovered in the figure of Félix José Weil, born in Argentina, a thinker of Marxist formation of wide scope who would play a central role for the formation, in theoretical and economic sense, of the famous School; character, however, marginalized and almost unknown in the studies of critical philosophy.

KEYWORDS: sponsor, marxism, IFS, foundation, Argentina.

\footnotetext{
${ }^{1}$ Profesor titular Docente, Tutor e Investigador Nivel "C" del Instituto de Educación Media Superior de la Ciudad de México (IEMS CDMX). Doctor en Filosofía por la Universidad Nacional Autónoma de México (UNAM). Emails: ogarciacorona@yahoo.com.mx /ogcorona1@gmail.com.
} 
Lo otro no existe: tal es la fe racional, la incurable creencia de la razón humana. Identidad = realidad, como si, a fin de cuentas, todo hubiera de ser, absoluta y necesariamente, uno y lo mismo. Pero lo otro no se deja eliminar; subsiste, persiste; es el hueso duro de roer en que la razón se deja los dientes.

Antonio Machado

Dentro del espectro epistemológico de la filosofía y de las ciencias sociales, la primera Escuela Frankfurt es reconocida por su vasta producción de ideas como uno de los principales legados del pensamiento crítico producido por Europa y los Estados Unidos a lo largo del siglo XX. Autores como Max Horkheimer, Theodor W. Adorno, Herbert Marcuse, Erich Fromm, Franz Neumann y Walter Benjamin ${ }^{2}$, entre otros, son identificados con aquella primera generación ${ }^{3}$. En sentido filosófico su reflexión potenció una crítica a la modernidad que ya ciertas tradiciones de pensamiento venían sugiriendo (el romanticismo alemán, Marx, Nietzsche, Freud y Heidegger principalmente); así mismo, las obras de Georg Lukács y Karl Korsch, fundadores del marxismo occidental, habrían introducido una positiva reflexión valorativa sobre el tradicional tema de las superestructuras ideológicas en el marxismo ${ }^{4}$, recuperando y reivindicando, más allá de la pura clase social y el proletariado como sujeto emancipador de la historia, los factores inherentes a lo simbólico y cultural del ser humano. Bajo tales presupuestos, la Teoría crítica (kritische Theorie) desarrollada por el grupo de intelectuales judíos a lo largo de décadas -casi hasta el último cuarto del siglo XX- es expresión de una cultura orientada por un tipo de racionalidad que termina por impactar la vida concreta de los seres humanos. Temas como la crítica a la razón instrumental, al nacionalsocialismo, al fascismo, al positivismo, al mito del progreso sin fin, a la cultura de masas, a la sociedad

\footnotetext{
2 Téngase en cuenta que Walter Benjamin nunca fue miembro formal del IFS, aun cuando tuvo algunas contribuciones en la Zeitschrift für Sozialforschung (Revista de investigación social) órgano de difusión del Instituto, fue marginado debido a diferencias teóricas con Horkheimer. Benjamin se quita la vida en Portbou (España) entre el 26 y el 27 de septiembre de 1940 bajo la angustia de ser tomado preso por paramilitares franquistas y ser deportado a Francia, nación en aquél momento tomada por los nazis.

${ }^{3}$ La segunda generación de la Escuela, ya hacia el último cuarto del siglo XX, aglutinó a pensadores como KarlOtto Apel, Jürgen Habermas, Alfred Schmidt y Albrecht Wellmer, entre otros, a la cual le continuó una tercera generación integrada hasta hoy por Axel Honneth y Helmut Dubiel, principalmente.

${ }^{4}$ Véase Lukács, 1970, principalmente su ensayo titulado "La cosificación y la consciencia del proletariado"; y Korsch, 1971.
} 
unidimensional, etc. son aspectos de un mismo fenómeno: la crisis civilizatoria de la cultura liberal capitalista en la modernidad.

La historia de la fundación de la Escuela se remonta, no obstante, hacia la década de los veinte -quizá a consecuencia de la Revolución rusa de 1917 y las fallidas alemana y húngara de 1918 y 1919 respectivamente- estando profundamente relacionada con un casi inexplorado personaje de nombre Félix José Weil, quien habría nacido en 1898 en América Latina, específicamente, en Buenos Aires, Argentina; país en que su padre Hermann Weil habría hecho fortuna como exportador de granos ${ }^{5}$. Hechos que, según veremos, conectan a la célebre Escuela alemana con América Latina y el marxismo. Desde un locus enuntiationis distinto al centro europeo está será la hipótesis más importante en este breve trabajo.

\title{
La fundación del Instituto de Investigaciones Sociales, América Latina y la Escuela de Frankfurt.
}

En mayo de 1923, el argentino Félix José Weil, doctor en ciencias políticas y economista, organizó en un hotel de Tübingen, Alemania, la "Primera Semana de trabajo Marxista” $\quad$ (Erste Marxistische Arbeitswoche, EMA) (Wiggershaus, 2010, p.24) -el más citado antecedente de la escuela frankfurtiana- que contó con la participación de Lukács, Korsch, Pollock, Sorge y Wittfogel, entre otros, todos menores de treinta años de edad (salvo Lukács y Korsch), quienes habrían de discutir y precisar, en el contexto de la frustrada revolución comunista y la derrota de la III Internacional, las nociones de un marxismo antidogmático y antipositivista.

Durante aquella semana las actividades consistieron en la discusión y análisis de textos de algunos de los participantes -jóvenes vinculados al Partido Comunista alemán- reunidos allí:

\begin{abstract}
Así se expusieron y debatieron, por ejemplo, la tesis doctoral de Weil [Vías y esencia de la socialización], un trabajo de Karl Wittfogel sobre la ciencia de la sociedad burguesa, y los manuscritos de Marxismo y Filosofía de Korsch y de Historia y conciencia de clase de Lukács. Las conclusiones de estos debates reafirmaron la importancia del materialismo dialéctico para la construcción de una filosofía de la praxis amparada en una conciencia proletaria que superase, mediante la crítica revolucionaria, las formas de la conciencia burguesa. Para ello debían suprimirse, primero, las relaciones materiales y objetivas que fundaban la sociedad burguesa como totalidad. Se trataba, en todo caso, de hacer valer la undécima tesis sobre Feuerbach elaborada por Marx: los filósofos debían superar la filosofía crítica pura, reflejo de una conciencia burguesa que se representaba como ajena e
\end{abstract}

\footnotetext{
${ }^{5}$ Sobre el tema Wiggershaus señala: "Su padre, Hermann Weil, que provenía de una familia de comerciantes judíos de la provincia de Baden, se había ido a Argentina en 1890, a los 22 años, como empleado de una empresa vendedora de cereales de Ámsterdam. En 1898 ya se había independizado y en poco tiempo había logrado hacer de su empresa una de las más grandes comercializadoras de cereales de Argentina [...] En 1908, el multimillonario había regresado a Alemania debido a una parálisis progresiva, y se había establecido en Fráncfort [...] con su esposa, su hija y su hijo (precisamente Félix, nacido en 1898 en Buenos Aires)". Wiggershaus, 2010, p. 23. También véase Jay, 1989, p.27-28 y Entel, 1999, p. 2002-203.
} 
independiente del mundo, y realizar la crítica científica que permitía transformar la realidad. (Rapoport, 2014, p. 204-205).

Posterior al éxito en las discusiones, el proyecto académico-social de Félix José Weil se centró en "financiar un instituto de ciencias sociales de tendencia crítica según el modelo del Instituto Marx-Engels de Moscú” (Rapoport, 2014, p. 28; Wiggershaus, 2010, p. 23). Nació pues la idea de crear un centro de estudios avanzados bajo la forma de un instituto de investigación autónomo a las restricciones financieras e ideológicas del estado alemán ${ }^{6}$. El Institut für Sozialforschung, IFS (Instituto de Investigaciones Sociales), que anteriormente habría pensado denominarse "Instituto para el marxismo", después "Instituto Felix Weil de Investigación Social", abrió sus puertas de manera oficial en el campus universitario de Frankfurt el 22 de junio de 1924.

Desde sus orígenes, con la fundamental cuota intelectual y financiera, el Instituto tuvo el interés de ocuparse de la historia del socialismo y los movimientos obreros ${ }^{7}$. El propio Félix José Weil haría lo propio con la clase obrera en Argentina (Rapoport, 2014, p. 189). Los estudios marxistas, de un talante poco ortodoxo, de acuerdo con las obras de Georg Lukács y Karl Korsch, intentaban superar el dogmatismo estático de la impronta soviética. Rolf Wiggershaus, historiador de la escuela, señala:

Félix Weil no se convirtió en empresario, ni en científico propiamente dicho; tampoco en artista; sino en un mecenas de izquierda [...] Weil formaba parte de ese grupo de jóvenes que, politizados por el resultado de la guerra y la Revolución de noviembre, estaban convencidos de la superioridad del socialismo como forma económica y de la posibilidad de realizarlo [...] Él financió en buena parte la editorial Malik, de Berlín, en la cual fueron publicadas entre otras obras, también Geschichte und Klassenbewußtsein de Georg Lukács. (Wiggershaus, 2010, p. 24)

Para los cronistas de la Escuela la historia del joven Weil se agota aquí. Si se le nombra es sólo como el mecenas burgués (junto con su padre Hermann) de un movimiento que se convertiría en referente esencial para la filosofía y las ciencias sociales pretendidamente críticas. No obstante, es importante no pasar por alto, siguiendo a Enrique Dussel, que los fondos para financiar el IFS (Instituto de Investigaciones Sociales) como centro de

\footnotetext{
${ }^{6}$ El director electo Kurt Albert Gerlach murió en octubre de 1923 y fue Carl Grünberg quien desempeñó la función hasta finales de 1930, en lo posterior tomaría el cargo Max Horkheimer hasta 1959.

${ }^{7}$ En "La situación actual de la filosofía social y las tareas de un Instituto de Investigación Social" Horkheimer destaca la labor de Grünberg, director previo del IFS, acerca de sus investigaciones sobre la historia del movimiento obrero, ya que señala: "ha sido posible reunir, además de archivos ricos en materiales, una biblioteca especializada y única de cerca de 50.000 volúmenes" (Horkheimer, 1993, p. 10). Por otro lado, es bien conocido que durante la segunda década del siglo pasado se inicia el Movimiento de la Fotografía Obrera en Alemania y Rusia con la finalidad de captar en imagen el horror de la miseria, la injusticia social y la explotación humana en las plantas industriales. Quizá, algunos de estos importantes documentos sean fruto del trabajo de la primera época del IFS.

${ }^{8}$ El subrayado es mío.
} 
investigación autónomo provinieron de América Latina, de un “judío argentino" (Dussel, 1994, p. 8$)^{9}$, y no de la burguesía alemana de Frankfurt. Hecho importante que pasa inadvertido o que en general se desconoce o incluso se oculta. Así, por ejemplo, desde una visión eurocéntrica, poco cuidadosa, algunos estudiosos de la escuela afirman:

Esta burguesía de Frankfurt, y sobre todo su parte judía, generó el impulso que desembocó en la fundación de la Universidad de Frankfurt [...] y fueron judíos aquellos que financiaron el Institut für Sozialforschung, independiente de la Universidad pero con ciertas relaciones institucionales con ella. Por el hecho de ser una institución académica privada, no eran aplicables las leyes antisemitas de la República de Weimar y, en consecuencia, los docentes judíos podían impartir clases e investigar, lo que en ninguna otra institución científica de Alemania antes del nacional socialismo era posible. (Gandler, 2009, p. 10). ${ }^{10}$

El proyecto académico-social de Weil, que sería financiado con capital proveniente de la explotación y mano de obra del suelo y recurso humano argentino, implicó muy tempranamente, como tarea primordial del grupo, una crítica al marxismo soviético, pero, a su vez, la búsqueda intelectual de un marxismo menos cerrado. "Su propósito -según el propio Weil- fue la esperanza de que las distintas tendencias marxistas, si se les concedía una oportunidad para discutirlo conjuntamente, pudieran arribar a un marxismo 'puro' o "verdadero"” (Jay, 1989, p. 28) ${ }^{11}$. El febril contexto político, económico y cultural de la Europa de la primera mitad del siglo XX revelaba complejos aspectos, mismos que exigían comenzar la elaboración de un análisis filosófico material con categorías políticas y económicas. La Revolución de Octubre parecía abrir nuevas posibilidades en el anquilosado espectro político continental. La ascensión de los soviets había generado profundas expectativas sociales que inspiraron diversos movimientos obreros en toda Europa. La revolución alemana de 1918 y la húngara de 1919 son claros ejemplos, aunque socialmente con precarios resultados. Los hechos demandaban una seria revisión de las estrategias teórico-prácticas para alcanzar el socialismo. El marxismo-leninismo había develado la existencia de una fuerza social que admitía vislumbrar un horizonte político capaz de influir en la transformación social con objeto de superar la explotación y el sufrimiento humano.

La importancia de Félix José Weil, más allá de ser considerado un generoso mecenas de izquierda, será -según nuestra hipótesis- mucho más radical. Una pregunta clave, si hurgamos

\footnotetext{
${ }^{9}$ Más precisamente de un judío-católico argentino. "En esa urbe [Buenos Aires], que estaba dando un salto completo a la modernidad, iba a nacer el 8 de febrero de 1898 Félix J. Weil, a quien sus padres declararon católico, pensando que eso le serviría para convivir mejor en el país que habían adoptado y que los había enriquecido." Rapoport, 2014, p. 125.

${ }^{10}$ Es claro que muchos desconoce que los fondos económicos iniciales para fundar el IFS provinieron de América Latina, de una burguesía judía que, aunque de origen alemán, se estableció durante años en Argentina dedicándose a la explotación de mano de obra para la producción y exportación de cereales, recurso que por largo tiempo sirvió de alimento a Europa.

${ }^{11}$ Epístola de Weil a Paul Brines, 10 de enero de 1971.
} 
en la vida de este desconocido personaje (y aun contradictorio por su propia circunstancia), podría ser la siguiente: ¿Qué factores propiciaron la conciencia crítica de un joven burgués, nacido en una urbe latinoamericana, para proponer, siendo parte de una acaudalada familia agroexportadora, un proyecto de investigación marxista de alto nivel? Sobre la infancia del joven Weil en la Argentina, a principios del siglo XX, el historiador Mario Rapoport, en un espléndido trabajo ${ }^{12}$, escribe:

Esa vida, de comodidades y lujo, sería cuestionada desde muy temprano por el niño, que a diario vivía, en el interior de su casa, las desigualdades sociales y de clase existentes entre su familia y sus sirvientes. Félix pasaba gran parte de sus días junto a Antonio, amigo de la infancia, su «hermano de leche», que además era hijo de la cocinera indígena, Juana, y del chofer de la familia, y con quien iban juntos a la escuela primaria. Tal vez este sentimiento fue el que le despertase su primera inquietud social cuando un día su padre le dijo: «Nuestra estancia me la forjé yo sólo con mi trabajo». En ese momento, Félix le recordó: «Es demasiado grande para nosotros. Antonio, sus hermanos y sus padres duermen todos en una pequeña pieza. ¿Por qué nosotros tenemos tanto lugar y otros tan poco?». Entonces Hermann, enojado, le respondió: «¿No entiendes que todo esto lo tengo porque me lo gané trabajando?». Tal vez esa fue, por primera vez, una respuesta paterna que no le satisfizo. Weil recuerda con cierta amargura que «jugaba a menudo con Antonio, íbamos a la misma escuela primaria, sus padres trabajaban para mi familia, yo era casi uno de ellos, pero Antonio no era uno de los nuestros». (Rapoport, 2014, p. 129).

Sus experiencias de vida en América Latina marcarían, muy a pesar de su posición familiar, un tipo de sensibilidad social y de observación crítica que se desarrollaría debido a sus estrechos vínculos con los trabajadores domésticos al servicio de la casa Weil durante los años más importantes de su niñez. El contraste respecto a su propia clase y la situación de los trabajadores nunca le pareció natural y, por el contrario, le indignó ser testigo directo de tan radical asimetría. De forma cotidiana advertía diferencias sociales que juzgaba como injustas pero que era incapaz de explicarse a tan corta edad y, menos aún, con las objeciones ofrecidas por su padre.

Otras experiencias infantiles que quizá tocaron su sensibilidad ocurrieron cuando era testigo frecuente de los despidos de aprendices o trabajadores de la compañía Weil. "Félix recibía así una de las primeras lecciones sobre la realidad de la empresa, a la que más tarde

\footnotetext{
${ }^{12}$ Su obra se titula: Bolchevique de salón. Vida de Félix J. Weil, el fundador argentino de la Escuela de Frankfurt. El controvertido epíteto "bolchevique de salón" -que pudiese interpretarse de variadas formas- aparece también en la monumental obra de Wiggershaus, La Escuela de Fráncfort; sobre Félix José Weil señala lo sigueinte: "Como «bolchevique de salón» colaboró en los años veinte en la periferia del ala derecha del Kommunistische Partei Deutschlands (KPD) [Partido Comunista Alemán]. Nunca se afilió al partido, aunque tenía una estrecha amistad con Clara Zetkin y Paul Frölich, y se había casado con la hija de un viejo socialista y buena amiga de Zetkin. Él financió en buena parte la editorial Malik, de Berlín, en la cual fueron publicadas, entre otras obras, también Geschichte und Klassenbewußtsein [Historia y conciencia de clase], de Georg Lukács" (Wiggershaus, 2010, p. 24). La obra del economista e historiador argentino Mario Rapoport es la primera que dedica -basándose en buena parte en las memorias (Weil, 1984) del propio "judío argentino", pero también por contactos con la familia Weil todavía en Argentina- una investigación biográfica a Félix José Weil, misma de la que nos servimos -no habiendo otro material- respecto a sus vivencias de temprana edad y juventud.
} 
debería dirigir contra su propia voluntad, como producto de la herencia paterna" (Weil, 1984, p. 19. Apud, Rapoport, 2014, p. 130-131). Sobre la realidad del latifundio, comenta en sus memorias, "que en la Argentina una mala cosecha podía arruinar a una familia de campesinos nativos, que debía esperar hasta la próxima para ver si tenía mejor suerte" (Ibidem).

El pequeño Weil permaneció en Argentina hasta sus nueve años de edad, etapa latinoamericana que lo habría marcado para siempre y que, sin duda, habría contribuido a formarle un pensamiento crítico social que a futuro tendría interesantes resultados. En Sudamérica -donde regresaría en múltiples ocasiones- había crecido usando la lengua castellana de forma habitual; la escuela, sus amigos y su red social más inmediata así lo requerían. Aunque también había sido educado -de acuerdo con las costumbres de la alta burguesía- por una institutriz inglesa quien le había enseñado lengua y cultura anglosajona. Sin embargo, su lengua materna era el alemán, que usaba siempre para hablar con su madre. El pequeño Weil había crecido manejando cotidianamente tres lenguas, elemento multicultural que le aportaría un horizonte social de amplio espectro.

Para 1907, con la finalidad de que el primogénito continuara sus estudios, había sido enviado al Goethe-Gymnasium en Frankfurt. El cambio de residencia obedecía, también, a que sus padres requerían atención médica; su madre por un cáncer avanzado que le quitaría la vida en 1912, mientras que su padre había contraído sífilis. Por otro lado, su abuela paterna radicaba en esa misma ciudad, por lo que se abría una nueva etapa en su vida familiar (Rapoport, 2014, p. 133) ${ }^{13}$. Durante ese periodo entró en contacto con la literatura europea, autores como Goethe, Voltaire o Balzac fueron de su agrado, aunque el naturalismo de Émile Zola lo tocó especialmente. Al terminar su bachillerato en 1916 ingresó a la Facultad de Derecho de la Universidad de Frankfurt con la finalidad de hacer un doctorado en Ciencias políticas. Fue ahí donde entró en contacto con estudiantes provenientes de familias pudientes, como Friedrich Pollock y Max Horkheimer. Momento además en que imbuido por una causa patriótica quiso alistarse al ejército alemán, petición que le sería denegada debido a su nacionalidad argentina.

La revolución alemana de 1918 significó para el joven Weil el año de su transformación definitiva al socialismo. Como militante activo ofreció sus servicios al consejo local de trabajadores y soldados, siendo nombrado comandante de patrullaje de la policía local, constituida por trabajadores opositores a las tropas de la monarquía. Se trataba de defender las conquistas de la revolución y de velar por la tranquilidad de los ciudadanos. El propio Weil cuanta en sus memorias que estando en la jefatura de policía:

\footnotetext{
${ }^{13}$ Hermann Weil moriría hasta 1927
} 
Un trabajador y combatiente de la socialdemocracia le facilitó el libro del partido que contenía el Programa de Erfurt de 1891. A partir de su lectura, Félix relataba: «por la mañana comprendí que había sido golpeado de tal manera que yo, apenas de la edad de veinte años, heredero principal de un hombre muy rico, y como tal también copropietario de una empresa con cientos de filiales en todo el mundo [...] venía a descubrir en ese momento que era socialista [...] Sin duda, mis sentimientos estaban del lado del socialismo, y seguramente desde hacía mucho tiempo ya. ¡Tan sólo que no había sido consciente de mis propias ideas!». (Weil, 1984, III-IV. Apud. Rapoport, 2014, p. 168.)

El Programa de Erfurt, elaborado por Karl Kautsky -y criticado por Engels-, declaraba la necesidad de la propiedad socialista de los medios de producción y, con ello, la muerte del capitalismo. El Programa había sido adoptado parcialmente por el Partido Social Demócrata de Alemania (SPD) desde 1891. De acuerdo con su autor la transformación socialista de la sociedad debía ser efectuada por un gobierno legitimado por elecciones democráticas, lo que significaba que si el poder político no era conquistado sería imposible la transformación de la sociedad. Más que por la revolución los socialistas debían luchar por mejorar la vida de los trabajadores, pues, debido a sus propias contradicciones, tarde que temprano, el capitalismo caería de forma inevitable. De acuerdo con Kautsky, aunque el capitalismo había evolucionado elevando los salarios y el papel de las organizaciones gremiales, simultáneamente, había surgido el revisionismo, por ejemplo de un Bernstein, caracterizado por señalar que varios conceptos de Marx eran falsos o bien anacrónicos. Además de limitar las metas del partido a meras conquistas democráticas.

La inclinación de Weil hacia el socialismo requería complementos teóricos; Marx se volvía, pues, absolutamente necesario. Durante 1919 Weil se traslada a Jena para participar en las jornadas de Grupos de Estudiantes Socialistas de Alemania donde conoció y trabó fuerte amistad con Karl Korsch, profesor de derecho en la Universidad de Tübingen. También se relacionó profundamente con Clara Zetkin, dirigente feminista que contribuyó a establecer el Día Internacional de la Mujer, y quien además fue fundadora del Partido Comunista Alemán junto con Rosa Luxemburgo y Karl Liebnecht. De los diálogos con Korsch y Zetkin, Weil produjo un artículo que sentaría las bases para su futura tesis doctoral titulado "Vías y esencia de la socialización” («Wesen und Wege der Sozialisieirung») (Rapoport, 2014, p. 198). Concepto que en aquel momento era disputado por la izquierda y la derecha de acuerdo a sus particulares intereses. El trabajo, pensado para el curso de Wilbrandt -su director de tesis- fue publicado en Consejo Obrero. Semanario del Socialismo Práctico, en el que Korsch participaba como miembro de la redacción.

En abril de 1920, Weil obtiene el doctorado con la investigación titulada "Socialización, intento de fundamentación conceptual, además de una crítica de los planes de socialización" 
(Sozialisierung Versuch, eine begrifflichen Grundlegung nebst einer Kritik der Sozialisierungspläne), calificada por su director como excelente (Rapoport, 2014, p. 179). Trabajo que, en múltiples sentidos, reflejaba la tensión entre sus ideas socialistas y su situación de empresario acaudalado. Un año después la investigación saldría publicada en el séptimo fascículo de la serie Socialismo Práctico dirigida por Karl Korsch (Rapoport, 2014, p. 201). Para Weil la teoría marxista, más allá de su acartonada ortodoxia, requería una auténtica búsqueda que condujera, a partir de su marco conceptual, a otorgar claridad a los movimientos de transformación social. Teoría y praxis serían para él elementos indisolubles. Así, después de viajar a Sudamérica y hacer estudios de la clase obrera argentina en 1922, vuelve a Frankfurt con la idea de analizar los procesos revolucionarios, y afinar el tema de la socialización, así como continuar los debates en torno a las diversas corrientes del marxismo. (Rapoport, 2014, p. 202).

Llegamos, pues, a un conocido pasaje. Será en Tübingen, en el verano de 1923 que, a manera de seminario, se organizó la Primera Semana de Trabajo Marxista, EMA (Erste Marxistische Arbeitswoche). Korsch, Lukács, Pollock, Wittfogel y Sorge, entre otros, habían atendido al llamado. A nivel historiográfico, el problema que se presenta al partir de este punto -como casi todos los estudiosos de la Escuela- es que, paradójicamente, se omiten los antecedentes, de formación teórica y de experiencia vital (biográfica), de quien fuera su principal promotor, identificándolo, simplemente, como el mecenas del grupo. De la citada experiencia surgirá en el joven Weil la idea de formalizar el seminario, creando un centro de estudios en ciencias sociales bajo la forma de un instituto autónomo, análogo al Instituto MarxEngels de Moscú que, poco tiempo después, comenzará a edificarse.

\footnotetext{
Los buenos resultados del seminario realizado despertaron el interés de Félix por institucionalizar la discusión del marxismo más allá de los límites forjados por la academia alemana y la demarcación ideológica impuesta por el KPD [Kommunistische Partei Deutschlands (Partido Comunista de Alemania)]. Vio así necesario crear una institución de carácter permanente que tuviera un mayor alcance que los seminarios periódicos. Tanto Félix, que ya disponía de la fortuna heredada de su difunta madre, como Hermann Weil disponían de los medios financieros para este fin y proveyeron el dinero que permitió la creación del Instituto para la Investigación Social. (Rapoport, 2014, p. 209).
}

Félix José Weil había pagado personalmente las instalaciones para albergar al instituto, el edificio y su biblioteca con la fortuna heredada de su madre, mientras que el padre, Hermann, se había comprometido a otorgar una donación anual para asegurar el cumplimiento sostenido de sus objetivos, "compromiso que también asumían sus herederos [...] el contrato equivalía a un importe de 30.147 dólares estadounidenses, lo cual cubría completamente el presupuesto del 
instituto (el ingreso mensual de un asistente era en ese entonces de aproximadamente 50 dólares)". (Rapoport, 2014, p. 2011).

En una nueva historia mundial de la filosofía se hace necesario difundir el legado de Félix José Weil, no sólo respecto a la fundación del IFS (Instituto de Investigaciones Sociales), sino como pensador y activista de alcance cosmopolita. Es poco conocido que hacia 1944, publica (en Nueva York) The Argentine Riddle (El enigma argentino ${ }^{14}$ ), novedosa investigación que recoge sus observaciones sobre la clase obrera, la política y la economía del país donde nació, y en el que su padre haría fortuna. ${ }^{15}$

A pesar de vivir en ámbitos alejados del común de los argentinos, algo habría sucedido en su percepción del país desde esa infancia para que luego le dedicara su único libro, que aunque centrado en los años treinta y cuarenta, abarca casi medio siglo de la historia argentina, prácticamente los mismos de su propia vida cuando lo escribió. (Rapoport, 2014, p. 131).

A Weil le intrigaba el atraso argentino, se preguntaba por las condiciones económicas y políticas de un defectuoso proceso de industrialización y las posibilidades de superarlo; sus análisis son profundos y sus hipótesis bastante sugerentes considerando, por ejemplo, la llamada teoría de la dependencia que más tarde sería desarrollada en América Latina ${ }^{16}$. Weil también contribuyó con el Partido Comunista Argentino (PCA); participó activamente desde la primera mitad de la década de los veinte, en su sede de Buenos Aires, con anuencia de Grigori Zinóviev líder de la Internacional Comunista en Rusia ${ }^{17}$. En Argentina, fue pionero -previo a la fundación del Instituto de Investigaciones Sociales de inspiración marxista- en estudiar el movimiento obrero, del cual observaba:

Su tendencia antipolítica, anticentralista, carente de unidad y de conciencia de clase estaba originada [...] en condiciones estructurales del capitalismo argentino, aún en ciernes, y subordinado como semicolonial en el escenario internacional. (Rapoport, 2014, p. 198).

No obstante:

A partir del reconocimiento de las particularidades, históricas y presentes, del movimiento obrero local, sus fortalezas y debilidades, Weil pretendía desbrozar el camino para la transformación del PCA [Partido Comunista Argentino] en la vanguardia de la clase obrera argentina, similar al bolchevique en la URSS. (Rapoport, 2014, p. 192)

\footnotetext{
${ }^{14}$ Coincidencia que en ese mismo año (1944) Horkheimer y Adorno publican su célebre Dialektik der Aufklärung (Dialéctica de la Ilustración), dato relevante si consideramos que los frankfurtianos jamás miraron hacia América Latina.

${ }^{15}$ Material reeditado en Argentina en 2010 por Ediciones Biblioteca Nacional.

16 Siguiendo la hipótesis de Enrique Dussel será André Gunder Frank, con clara conciencia de una "totalidad dialéctica" antifuncionalista, quien lanza por vez primera, hacia 1963, la hipótesis central sobre la dependencia. Para él "la estructura de este sistema es lo que constituye la causa histórica y el determinante aún contemporáneo del subdesarrollo. La estructura doméstica del subdesarrollo en países subdesarrollados es sólo una parte del sistema mundial" Dussel, 1988, p.323. Aunque es conocido que desde 1961 Celso Furtado, en Brasil, había publicado su obra Desarrollo y subdesarrollo.

${ }^{17}$ Para 1926 Grigori Zinóviev perdió la dirección del Komintern y fue sustituido por Nikolai Bujarin.
} 
Más allá de la rigidez de un proyecto intelectual su investigación se nutría de diversas motivaciones con efecto práctico hacia futuras tareas sociales. Argentina, como su primera patria, le habría heredado elementos estructurales de conciencia humana y social que le serían indelebles, y que a futuro articularía, quizá, en su búsqueda de un marxismo que sirviera a la transformación del sistema. En sus memorias escribe:

En los años que pasé en Alemania casi había olvidado lo que era una familia [...]». Pero no tanto por la suya propia. «Cuando sentía nostalgia -dice- era más por Antonio, mi yegua Matilda, el fuerte aroma mezclado de las plantas y ante todo por las personas. En Argentina se podía dirigir una mirada cordial a un desconocido en la calle y uno recibía en respuesta un saludo amistoso [...]. Esto por supuesto pasaba sólo entre la gente sencilla, los que iban de a pie, los que llevaban a los niños de la mano y se vestían con ropas diferentes a las mías y a las de mi familia. En Alemania no me hubiera atrevido a saludar amistosamente a un desconocido en la calle. Para los alemanes de aquellos tiempos la desconfianza les parecía tan natural como el saludo entre las personas para los trabajadores argentinos. (Rapoport, 2014, p. 132)

Por otro lado, uno de los acontecimientos más importantes en la historia del pensamiento crítico -que implica también a nuestro personaje-, se relaciona con los inicios de la difusión mundial de la gran obra de Marx y Engels. Es en general desconocido que Félix José Weil "fue quien logró que en los años 20 el flamante Instituto Marx-Engels creado por la Revolución Rusa acordara con la socialdemocracia alemana que entregara copias de toda la obra de los fundadores del socialismo científico que se concretó en la edición MEGA en alemán y ruso de 40 volúmenes de lo que se conocía entonces de ellos"18. Al respecto Rapoport comenta:

Una de las principales tareas de la Sociedad de Investigación Social, la fundación que financiaba el IFSy cuyos titulares eran Hermann y Félix Weil, fue su participación activa en la mediación entre el Instituto Marx-Engels de Moscú (IMEM) y el Partido Socialdemócrata alemán al firmar un contrato para que el IMEM editara las obras completas de Marx y Engels (conocidas como MEGA Marx-Engels Gesamtausgabe), a partir de los manuscritos que estaban en poder del $\mathrm{SDP}^{19}$ en Berlín desde que Engels los dejara en manos de Eduard Bernstein y August Bebel. La tarea que encaró el IFS no sólo se remitía a la «despolitización» de las relaciones entre la socialdemocracia alemana y el IMEM, sino que además suponía una asistencia práctica y la prestación de las instalaciones para que se pudiera llevar a cabo el trabajo en Frankfurt. (Rapoport, 2014, p. 226-228).

La historia del pensamiento crítico mundial con la reproducción y consiguiente difusión de la obra de Marx y Engels, durante la segunda década del siglo XX, marcó un significativo avance, lo que comprendió tremenda empresa al considerar su complicado proceso; las limitaciones técnicas de la época, la propia geopolítica e incluso la discrepancia ideológica entre las izquierdas son variables a considerar.

Los datos significativos, respecto a lo mejor que ha producido la izquierda crítica, que se vinculan a la biografía de este ignoto y activo pensador son extraordinarios. Valga un caso

\footnotetext{
${ }^{18}$ Gilbert, I. "Un argentino en la Escuela de Frankfurt" Revista de Cultura N. Clarín, 28/10/2014.

${ }^{19}$ Sozialdemokratische Partei Deutschlands (SPD) Partido Socialdemócrata Alemán.
} 
más. Weil también se hizo partícipe en el filme El acorazado Potemkin, la insigne y revolucionaria obra de Sergei Eisenstein; "una propuesta de los rusos que compró y luego editó agregando diálogos en alemán e incorporándole la música de una orquesta de setenta destacados instrumentistas que acompañaban a la película tocando composiciones rusas con lo que destacaba aún más -según Weil- el genio de Eisenstein”. (Rapoport, 2014, p. 241).

La doble vida de Weil, como empresario de élite y en la clandestinidad como intelectual vinculado a la internacional comunista, además de su mecenazgo a proyectos de izquierda fue una constante durante toda su vida ${ }^{20}$. En relación al Instituto de Investigaciones Sociales (IFS) todo parece indicar que a partir de 1931, cuando Max Horkheimer asume la dirección, hubo diferencias respecto a las líneas de investigación y objetivos pensados por el propio Weil.

\begin{abstract}
La formación de ambos había sido completamente distinta. Weil fue ganado por el marxismo no sólo por sus estudios -era economista y su tesis doctoral trataba del tema clave la socialización- sino también por su militancia estudiantil y política. Sin ser miembro estuvo estrechamente ligado a los espartaquistas y luego al Partido Comunista Alemán (KPD), al menos hasta principios de los años treinta, a lo que se sumaba su vinculación directa a través de la edición de las MEGA y otras actividades relacionadas con la Unión Soviética. Horkheimer, en cambio, hizo su tesis sobre Kant, admiraba a Schopenhauer [...] se había formado como filósofo, al igual que Adorno, con Hans Cornelius, un estudioso de Kant. Era más afín a Hegel que a Marx [...] En el fondo, la Teoría Crítica poco tenía que ver con las intenciones iniciales de Weil de conformar un instituto marxista, y la llamada Escuela de Frankfurt resultó al fin y al cabo un conjunto de brillantes intelectuales con distintos propósitos y objetivos. En cambio [...] hacia el fin de su vida Félix seguía interesándose por las corrientes marxistas contemporáneas. (Rapoport, 2014, p. 257-258).
\end{abstract}

Con todo y las desavenencias Weil nunca rompió con el grupo de Horkheimer ${ }^{21}$, incluso siendo testigo del progresivo alejamiento de Marx y especialmente respecto al vínculo práctico con movimientos sociales o políticos. Ya para 1968 y 1969 sabía que ellos, Horkheimer y Adorno, no estaban de acuerdo con las manifestaciones estudiantiles, enterándose además del trágico desenlace entre Adorno, los estudiantes y la policía en la Universidad de Frankfort ${ }^{22}$. En sus memorias Felix Weil señala:

\footnotetext{
${ }^{20}$ En la clandestinidad usaba incluso seudónimos. Lucio había sido el primer nombre puesto por sus padres, pero que por desagrado eliminaría formalmente, aunque era el seudónimo que solía usar (Lucius, en versión latina), además del de Beatus, al reunirse con grupos de la internacional comunista o movimientos obreros.

${ }^{21}$ Weil "tampoco le perdonó a Max [Horkheimer] el haberle dicho a uno de sus biógrafos que «Weil llevaba la vida de un docente que, salvo sus esfuerzos por las finanzas del instituto y ocasionalmente las tareas en el archivo Grünberg, no tenía interés en el trabajo del instituto». Algo por lo cual, en su último encuentro, en 1973, Horkheimer se disculpó. Pero la semblanza que da Weil de su antiguo amigo es más bien piadosa y algo burlona. «Estoy contento por vos, Max», le había dicho Weil al despedirlo, cuando parecía gravemente enfermo y aquel le confesaba haber encontrado la fe: «Continuez ainsi», lo estimuló. Tres días después Horkheimer falleció" (Rapoport, 2014, p. 258-259).

${ }^{22}$ El propio Lukács, desde la década de los treinta, habría denunciado la hostilidad de Adorno por la praxis, así como la posición ideológica burguesa de una pretendida teoría purista sin referencia a sujetos sociales de lucha. Véase Lukács, 2010, Prefacio; también Infranca, 2007, p. 31-47. Décadas más tarde, durante 1968 y 1969 dichos señalamientos serán confirmados; el conservadurismo político de Adorno, así como su relación conflictiva con los movimientos estudiantiles (que se declaraban abiertamente seguidores de sus obras) quedó de manifiesto. En 1968 Adorno decidió llamar a la policía para desalojar a un grupo de estudiantes del Instituto de Investigaciones Sociales
} 
Si hubiera planteado abiertamente mi oposición le habría hecho daño públicamente al primer instituto, para alegría de sus detractores, y a los estudiantes que confiaban en mí, tal vez para el resto de sus vidas. Las donaciones de mi padre y las mías habían estado destinadas para un determinado objetivo científico, pero ese objetivo ya no se cumplía. (Weil, 1984, p. 164. Apud, Rapoport, 2014, p. 259-260).

Quizá todo esto explica por qué Weil no publicó sus investigaciones como parte del grupo que él mismo fundó y financió, salvo en 1923 que el Instituto publicó su trabajo sobre la clase obrera en Argentina titulado Die Arbeiterbewegung in Argentinien (El movimiento obrero en Argentina ${ }^{23}$ ), lo cual tuvo el desafortunado efecto de hacerlo invisible respecto a la historia de la propia escuela. Respecto a la kritische Theorie su nombre y alcances, así como sus vínculos con América Latina, son prácticamente desconocidos. Rapoport señala que tal vez la decisión de no aparecer en el primer plano de aquel creativo grupo de investigadores pudo estar influenciado por el hecho de que él "no era verdaderamente alemán, y de suponer por eso que su propia carrera podría tener muchas trabas, agravadas por sus ideas marxistas, en el mundo académico germano" (Rapoport, 2014, p. 262), además de tener que dedicar tiempo a sus múltiples actividades como empresario. En tal sentido Weil mismo escribió: "Yo consideré mejor actuar desde un segundo plano. Esto lo mantuve a lo largo de toda mi vida" (Ibidem). De forma efectiva hasta su muerte, después de la de Adorno (1969) y Horkheimer (1973), en 1975.

Sobre el desconocimiento académico del fundador de la Escuela de Frankfurt, aun en su país de origen, Rapoport señala: "En la Argentina existen aún algunos velos que debemos levantar si pretendemos entender mejor nuestra propia historia como aquél que cubre la figura casi olvidada hasta hace pocos años de Félix José Weil [...]” (Rapoport, 2014, p. 21). En el mismo sentido, nosotros pensamos que esos velos continúan cubriendo, a través de un colonialismo epistemológico, a toda América Latina, y es hoy responsabilidad nuestra aprender el oficio de de-velar con el fin de posicionarnos críticamente -desde regiones epistemológicas alternativas- en la construcción de múltiples ideas y tradiciones hegemónicas en el pensamiento occidental. La propia historia de la filosofía mundial toma un giro particular en el tema de la Escuela de Frankfurt cuando introducimos estas novedosas variables. A Félix José Weil, en definitiva, hay que tratarle no como un mecenas de izquierda -fenómeno per se digno, análogo a lo que Engels hiciera con Marx ${ }^{24}$ - sino como auténtico pensador, cuyo legado intelectual ha sido olvidado y aún desconocido entre los miembros y estudiosos de aquella primera, y demás

\footnotetext{
(siendo él mismo su director) en la Universidad de Frankfurt acusándolos de intrusión al no compartir su lucha por una reforma universitaria. Véase Traverso, 2010, p. 189.

${ }^{23}$ Trabajo no conocido en los centros universitarios, pionero, no obstante, en los estudios de la clase obrera. Investigación que coincide además en el año de publicación (1923), y aun en aspectos temáticos, con Historia y conciencia de clase de György Lukács.

24 "El nuevo Engels" le llama Rapoport.
} 
generaciones de la Escuela. Su obra habrá de ser difundida e incluida en el corpus clásico del grupo de investigadores de aquella época. Surge el deber, por elemental justicia histórica, de recuperar al pensador argentino. Mario Rapoport ha puesto ya el ejemplo. Félix José Weil es, sin duda, el fundador del proyecto intelectual marxista más importante del siglo XX, lo que a futuro sería conocido como la primera Escuela de Frankfurt; proyecto marxista que, ya instalado en los Estados Unidos, sería progresivamente modificado.

Afirmamos, por tanto, que el vínculo entre América Latina y la Escuela de Frankfurt no sólo es definitivo sino fundacional. En primera instancia, es evidente que el proyecto intelectual para crear una institución académica de investigación marxista fue, de acuerdo con su formación académica, experiencias políticas y de vida, inspiración del propio Félix Weil. Así mismo, los recursos económicos que hicieron posible la creación del Instituto de Investigaciones Sociales -origen tradicional de la escuela- provinieron de "la renta de la tierra argentina" (Entel, 2005, p. 202), lo que posibilitó, al mismo tiempo, su independencia intelectual más allá de los límites academicistas y políticos de los centros universitarios alemanes en aquél abigarrado contexto social. Tomando en cuenta la diversidad de sus pensadores, incluyendo ahora al propio fundador, es aún más complejo hablar de una escuela frankfurtiana en sentido estricto. No olvidemos que la denominación Escuela "fue utilizada por Adorno mismo con evidente orgullo"; la "etiqueta asignada desde fuera" tomó fuerza en Estados Unidos después de que los investigadores -específicamente Adorno y Horkheimerregresaron del exilio a su patria (Wiggershaus, 2010, p. 9).

El objetivo aquí, en conclusión, ha sido hacer explícitos los vínculos entre la Escuela de Frankfurt y América Latina, poco conocidos o exiguamente estudiados, e incluso marginados desde el influjo hegemónico de una tradición eurocéntrica en los estudios academicistas de la Teoría crítica. Sacarlos a la luz significa ponerlos a discusión, pero además actualizarlos desde un punto de vista latinoamericano que dé cuenta de su propia evolución como parte de una historia de la filosofía tensionada entre varias tradiciones.

\section{REFERENCIAS}

DUSSEL, E. 1492 El encubrimiento del Otro. Hacia el origen del "mito de la Modernidad", La Paz: Plural Editores, 1994.

DUSSEL, E. Hacia un Marx desconocido. Un comentario a los manuscritos del 61-63, México: Siglo XXI, 1988.

ENTEL, A. Escuela de Frankfurt. Razón, arte y libertad, Buenos Aires: Eudeba, 2005. 
GANDLER, S. Fragmentos de Frankfurt, México: Siglo XXI, 2009.

GILBERT, I. "Un argentino en la Escuela de Frankfurt" En: Revista de Cultura N. Clarín, Buenos Aires, 25/10/2014.

HORKHEIMER, M. Between philosophy and social science. Select Early Writings, Cambridge: The MIT Press, 1993.

INFRANCA, A. y M. Vedda (comp.) György Lukács: Ética, Estética y Ontología, Buenos Aires: Colihue Universidad, 2007.

JAY, M. La imaginación dialéctica. Una historia de la Escuela de Frankfurt, Madrid: Taurus, 1989.

KORSCH, K. Marxismo y filosofía, México: Era, 1971.

LUKÁCS, G. Teoría de la novela, Buenos Aires: Ediciones Godot, 2010.

LUKÁCS, G. Historia y consciencia de clase, La Habana: Editorial de Ciencias Sociales del Instituto del Libro, 1970.

RAPOPORT, M. Bolchevique de salón. Vida de Félix J. Weil, el fundador argentino de la Escuela de Frankfurt, Buenos Aires: Debate, 2014.

TRAVERSO, E. "Theodor Adorno: retrato de un mandarín marxista". En: Bajo el volcán. Puebla, vol. 9, núm. 15, 2010, pp. 185-191.

WEIL, F. El enigma argentino, Buenos Aires: Ediciones Biblioteca Nacional, 2010.

WEIL, F. Erinnerungen (Memorias), Frankfurt am Main: Instituto de Historia Urbana/Stadtarchiv Frankfurt, 1984.

WIGGERSHAUS, R. La Escuela de Fráncfort, México: Fondo de Cultura Económica, 2010. 